\title{
Practices of Delivering Dispreferred Responses in English Talk Show Interaction*
}

\author{
Chunxiao $\mathrm{Wu}$ \\ Taishan University, China
}

\begin{abstract}
English talk shows have attracted a large group of audience with their humorous and relaxing features and these programmes are not only entertaining but also information-oriented, so the smooth progression of host-guest interaction is very important for producers, interactants, and the audience. However, the fact is that talk show interactants do not always construct their turns with collaborative efforts and the presence of dispreferred responses is not rare. With the data collected from ten episodes of Conan, the practices of delaying the occurrences of dispreferred responses and the practices of blurring them are generalized. The exploration of some possible causes of delivering dispreferred responses can lead to the conclusion that instead of being made arbitrarily, dispreferred responses could be delivered for lack of relevant knowledge, out of the consideration of modesty, and so on. Therefore, dispreferred responses are not definitely destructive to smooth communication and social solidarity since various devices can be used to mitigate the force of dispreferred responses and minimize potential threats to the face of interlocutors.
\end{abstract}

Index Terms - dispreferred responses, talk show, conversation analysis

\section{INTRODUCTION}

Talk shows, with their entertaining and relaxing features, have become one type of the most popular programmes. These programmes are also information-oriented since they are expected to present to the audience as much information about guests as possible within a fixed period of time, so the smooth progression of host-guest interaction is crucial.

Interaction cannot proceed smoothly without the collaboration of participants, but there is no shortage of dispreferred responses in interaction since participants in every kind of social setting have diverse interests and stances which are all managed in talk-in-interaction (Schegloff, 2007, p. 72). Thus it is not unusual to find that talk show interactants do not always construct their conversations with collaborative efforts and dispreferred responses can be noticed frequently.

To examine whether dispreferred responses will definitely hinder the smooth progression of host-guest interaction in talk shows or not and whether they are absolutely destructive to interactants' social solidarity or not, this study explores how and why the dispreferred responses are delivered in the data.

\section{DATA AND METHOD}

The data in this study are collected from ten episodes of Conan. For easy identification of the dispreferred responses and the practices of delivering them, only the interaction between two parties, that is, the interaction between the host and one guest at a time is transcribed and analyzed. Given the applicability of the conversation analytic approach to the transcription and description of naturally-occurring data, this approach is taken in the examination of dispreferred responses in this study.

The host-guest interaction in the data was transcribed according to the transcription conventions proposed by G. Jefferson (Atkinson \& Heritage, 1984, pp. ix-Xvi). Although the subtitles added to the videos can be referred to, great attention is still required during the transcription since only modified utterances are presented in the subtitles while minute conversational details such as rising intonations, rushed talk, interruptions, repair, and so on, are not displayed manifestly. These details are also important for facilitating the identification and interpretation of dispreferred responses in talk-in-interaction. Besides, some utterances are even omitted from the subtitles. After the preliminary transcription, the transcripts were carefully checked and double-checked.

During the analysis of the data, some practices of delivering dispreferred responses are tentatively generalized and some potential factors behind the delivery of dispreferred responses are explored to figure out some possible influences of dispreferred responses on smooth interaction and social solidarity.

\section{PRACTICES OF DELIVERING DiSPREFERRED RESPONSES}

It is not only through linguistic devices but also through practices that conversation participants construct their verbal conduct and understand others' talk during their interaction (Drew, 2004, p. 99). Therefore, one of the aims of conversation analytic research is to identify these practices that enable participants to construct their turns and

\footnotetext{
${ }^{*}$ Project Supported by Scientific Research Fund for Young Teachers of Taishan University (Project No.: QN-02-201922)
} 
sequences to do and to be recognized as doing what they intend to do, that is, to identify the practices that underlie the accountability of their verbal conduct (ibid., p. 94). In this study, the author attempts to explore some practices of delivering dispreferred responses in the data at the level of turns and of sequences.

\section{A. Delaying the Occurrences of Dispreferred Responses}

One practice of delivering dispreferred responses in the data is delaying their occurrences, which can be performed both at the level of turns and at the level of sequences, that is, through turn design and through sequential manipulation (Yu \& Wu, 2015).

a. Turn Design

Turn is the most fundamental unit in conversation analysis. Heritage (1984) claimed that the realization of specific features in the turn design of preferred and dispreferred responses is associated with the affiliative and disaffiliative characters of the responses since preferred responses are invariably affiliative and supportive of social solidarity while dispreferred responses are largely disaffiliative and destructive of social solidarity (pp. 268-269). At this level, the author examines how the talk show interactants construct their turns in order to be responsive to prior turns (Drew, 2004, p. 99).

Excerpt 1 ("H" refers to the host and "G" refers to the guest, the same below)

$01 \mathrm{H}$ : You um you like to dance $\uparrow$ you consider yourself not a bad dancer $\uparrow$ is that right?

$02 \mathrm{G}: \rightarrow$ (.) I don't know about that

Excerpt 2

01 H: Er we have a clip here um from Paddington, anything you can tell us about this?

$02 \mathrm{G}: \rightarrow$ Um::: nope

Expected answers are preferred in response to questions while unexpected answers and non-answers are dispreferred (Tanaka, 2005). In the interactions displayed by the above two excerpts, some dispreferred responses are made by the guests (02, Excerpt 1; 02, Excerpt 2), but the turn designs in these instances all help delay the occurrences of the dispreferred responses and enable the guests to deliver the dispreferred responses in a mitigated way.

According to Molenaar and Smit (1996), a preferred response in circumstances like that of Excerpt 1 is generally an unreserved answer of "yes" or "no", sometimes with an explanation added to the direct answer. Although both positive and negative answers are adequate responses, they are not equivalent (Hutchby \& Wooffitt, 1998, p. 43). In the context of the exchange shown by Excerpt 1, a positive answer indicates that the proposition implied in the host's question is agreed with while a negative answer indicates that this proposition is not supported (Molenaar \& Smit, 1996). After the host completes his turn with a tag question which is a request for confirmation and also functions as a device for minimizing the risk of disagreement, he expects an affirmative response from the guest (Englert, 2010). But the guest does not immediately provide the expected response, instead, the unexpected and dispreferred response made by the guest is delayed by the noticeable and meaningful period of silence at the turn-initial position.

Likewise, in the interaction displayed by Excerpt 2, the guest refuses to provide the information required by the host, which is also of dispreferred nature. However, the guest delivers this dispreferred response in a hesitant manner, which is indicated by the discourse marker "Um" and the prolonging of its pronunciation.

Excerpt 3

$01 \mathrm{H}: \quad$ They're animal yeah=

$02 \mathrm{G}: \quad=$ A reptile

$03 \mathrm{H}: \rightarrow$ A reptile $\uparrow$ yes $\uparrow$ but I don’t (.) I (.) I- I (.) like all kinds of animals=

$04 \mathrm{G}: \quad=\mathrm{OK}=$

$05 \mathrm{H}: \rightarrow=>$ That means $<$ I really like (.) I even like bugs but (.) but snakes I find (.) a little bit

$06 \rightarrow$ creepy

Before the interaction shown by Excerpt 3, the guest admitted that she loves snakes which she does not regard as strange since she believes that snakes are also animals. In this interaction, after the guest argues that snakes are reptiles in Line 02, the host first agrees with this assertion by repeating the guest's prior utterance in rising intonation which can function as a kind of mitigator (Rees-Miller, 2000). Besides, the host's repetition of the guest's prior utterance with an altered intonation can also be an index of disagreement (ibid.). After the partial repetition, the host expresses his different attitude towards snakes $(05 \& 06)$ with the use of the contrastive marker "but" which indexes "a denial of expectation or something contrary to expectations" (Park, 1998). The expression of disagreement by the host is delayed by the token agreement ("A reptile $\uparrow$ yes $\uparrow$ ”), the self-editing ("I don’t (.) I (.) I- I (.) like ..." "I really like (.) I even like"), and the intra-turn pauses, and this dispreferred response is not delivered until the second turn of the host if the assertion made by the guest in Line 02 is seen as the first turn in this exchange. Therefore, the practice of delaying dispreferred responses is realized not only through the turn design (e.g. 03), but also through the sequential manipulation $(03,05, \&$ 06).

b. Sequential Manipulation

Sequential structure is also a major concept in conversation analysis which can help build the coherence among utterances (Schegloff, 1990). The examination of sequential manipulation of delivering dispreference can facilitate the understanding of the resources and constraints provided by participants through performing certain actions (Bilmes, 1988). 


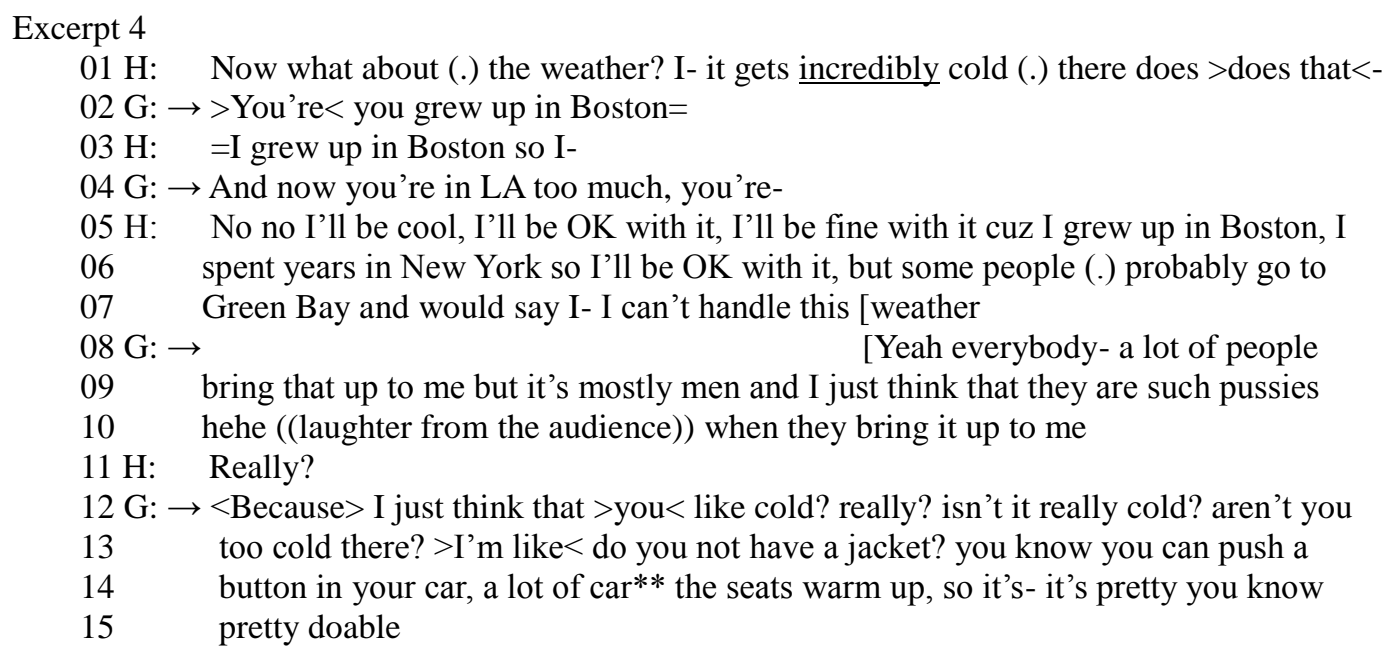

Just before this exchange, the guest mentioned that she has moved to Green Bay. Afterwards, the host initiates the topic of the weather of Green Bay and makes an assessment that "it gets incredibly cold" (01). We can finally judge from Line 15 that the guest regards the weather of Green Bay not as "incredibly cold" but as "pretty doable", which is in discord with the host's assessment in Line 01. However, the guest does not express her disagreement in Line 02 which immediately follows the completion of the host's first turn, instead, the guest shifts the discussion of the weather of Green Bay to the discussion of the host's adaptation to weather in different cities. It is only after the host refers to the weather of Green Bay again in Lines 06 and 07 that the guest returns to the topical agenda established by the host's question and assessment in Line 01, but the guest does not express her attitude toward the weather there until at the end of this excerpt, thus delaying the occurrence of the dispreferred response.

\section{B. Blurring Dispreferred Responses}

The talk show interactants often attempt to blur dispreferred responses or lessen their force with devices including hedges, explanations, topic shifts, and so on. The practice of blurring dispreferred responses is normally performed at turn level in the data, that is, it is generally performed by the speaker in the same turn where he or she delivers a dispreferred response.

Excerpt 5

$01 \mathrm{H}$ : But I was- I was down with doing (.) this trip with you $\uparrow$ and then you started to

02 describe, it wasn't just climbing up any mountain, I didn't realize $>$ that $<$ it was one

03 of those deals where you can get killed

$04 \mathrm{G}$ : No but yes, people (.) die [on the mountains sometimes but there're-

$05 \mathrm{H}$ : [Yeah no >let me

06 show<-

$07 \mathrm{G}: \quad$ There are harder ways to go up

$08 \mathrm{H}$ : How many people (.) I employ a lot of people, they don't want me to take that trip

09 ((Laughter from the audience))

$10 \mathrm{G}: \rightarrow$ I think some would $\uparrow$

Before the exchange displayed by this excerpt, the host mentioned that he was once invited by the guest to climb a mountain. In this exchange, the host regards it as dangerous to climb the mountain (03) and even claims that his colleagues do not want him to take the trip (08), with which the guest disagrees (10) but the guest expresses his disagreement in a mitigated way with the uncertainty marker "I think" prefacing his turn. Besides, the use of hedges ("some" and "would") and the rising intonation also help blur the dispreferred response (Rees-Miller, 2000).

Excerpt 6

$01 \mathrm{G}: \quad$ Are you a good skier?

$02 \mathrm{H}$ : I'm OK I'm- I'm called a terminal intermediate which means I- ((laughter from the

03 guest)) I'll forever be an intermediate no matter how long I ski, I'll be like [pretty

04 decent intermediate

$05 \mathrm{G}$ :

[Yeah

$06 \mathrm{H}: \quad$ Why are you so=

$07 \mathrm{G}: \rightarrow=$ That's true you never actually $>$ I mean $<$ I'll never do a black diamond ((turning to

08 the audience)) does anyone else ski?

After the host makes a self-deprecation that he will be "pretty decent intermediate" in skiing, the guest agrees with him (05), which is a dispreferred response since disagreement after a self-deprecating assessment is preferred to agreement (Pomerantz, 1984). Therefore, the host intends to ask the guest why she is so straightforward (06). However, his turn is interrupted by the guest before coming to a possible completion.

According to the assertion made by Tanaka (2008) that the use of "actually" can be confrontational and projects a 
forthcoming dispreferred response, it can be judged that the guest intends to make a negative assessment of the host's skiing skill in Line 07. However, she immediately realizes that this forthcoming negative assessment may damage the host's face, so she makes a false start with "I mean" and shifts to the description of herself. Besides, the guest even shifts her utterance recipient from the host to the audience by turning her face to the audience and attempts to have interaction with the audience by asking them a question "Does anyone else ski?" In this way, the guest blurs her dispreferred response through a false start and topic shifts.

With the practices of delivering dispreferred responses generalized in the data, it can be concluded that agenda-transforming responses can be adopted not only to delay the occurrences of dispreferred responses, but also to blur dispreferred responses by mitigating the force of them.

\section{POTENTIAL FACTORS BEHIND THE DELIVERY OF DISPREFERRED RESPONSES}

Dispreferred responses are not arbitrary linguistic choices made by interactants and there must be certain motives underlying the delivery of these responses. Three possible causes are tentatively explored in this research.

\section{A. Claiming Lack of Relevant Knowledge}

In some cases, the addressee does not provide the information which is in line with the questioner's contribution because the addressee does not know the required information (Molenaar \& Smit, 1996). In the following two exchanges, the guests cannot respond with the answers expected by the host (03, Excerpt 7; 02, Excerpt 8) and these dispreferred responses are all made with the guests' claiming that they do not have the relevant knowledge to respond to the host's questions in an appropriate manner.

Excerpt 7

$01 \mathrm{H}: \quad$ Rebel Wilson- by the way Rebel Wilson um leaked that there would be a Pitch

02 Perfect 3, what can you say for that

$03 \mathrm{G}: \rightarrow$ Oh god I- I have no idea I- I didn’t even find out about Pitch Perfect 2 until on

04 twitters so-

Excerpt 8

$01 \mathrm{H}$ : I have to ask you one last question, you're writing another book, what's it about

$02 \mathrm{G}: \rightarrow$ Um: shall I tell you the working title $\uparrow$ [cuz I can’t decide

$03 \mathrm{H}$ :

[Yeah

In the interaction displayed by Excerpt 7, the guest states explicitly that she has no idea of the answer to the host's question, thus directly rejecting the host's presumption that she knows the required information (ibid.). After the direct rejection, the guest gives explanation for her lack of the knowledge to respond to the host's question in an expected way: since she did not have the relevant knowledge about Pitch Perfect 2, the former serial of Pitch Perfect 3, it is quite natural that she does not have the relevant knowledge about Pitch Perfect 3 either. This explanation, to some extent, lessens the force of the dispreferred response delivered by the guest in the same turn. In the exchange shown by Excerpt 8, the guest does not claim her lack of knowledge as straightforwardly as the guest in the exchange shown by Excerpt 7. Instead, this guest first asks for the permission to introduce the "working title" of her book which is related to but does not correspond exactly to the host's question about the content of the book, followed by an explanation that she cannot decide the content of the book at that time. This guest shows her lack of the relevant knowledge to answer the host's question in an indirect and mitigated manner.

\section{B. Indicating Disalignment}

A dispreferred response conveys a stance which challenges "the warrantability of the accountable event" and often embodies disalignment with the interlocutor (Waring, 2012). In addition to the claimed lack of relevant knowledge, the talk show interactants also make dispreferred responses to show their disalignment with the assertion made by their interlocutors and this can be realized by the employment of some on-record devices, for example, disagreement.

Excerpt 9

$01 \mathrm{H}$ : > Let me< ask you this, you are quite tall, do you think y-

$02 \mathrm{G}: \rightarrow$ No no I'm very tall

Excerpt 10

$01 \mathrm{H}$ : I'm not really a Depp guy myself

02 ((Laughter))

03 G: $\rightarrow$ Who isn't a Depp guy, he's so nice he just seems-

The dispreferred responses made in the interactions exhibited by the above two excerpts are indicators of disalignment with the assessments or assertions made by the host in the prior turns. In the exchange shown by Excerpt 9 , the guest delivers a dispreferred response by negating directly the assessment made by the host ("you are quite tall") and then initiating an explicit other-repair ("quite" - "very") which is also of dispreferred nature (Pomerantz \& Heritage, 2013) since the execution of other-repair can topicalize a trouble source and make an error salient (Hutchby \& Wooffitt, 1998, p. 68). Therefore, the guest expresses her disalignment with the assessment made by the host in a direct and unmitigated way. 
In the exchange presented by Excerpt 10, after the host states that he is "not really a Depp guy", the guest utters a rhetorical question and offers an explanation for her question. Although the guest does not express her disagreement directly through explicit negation markers such as "no", "I disagree with you", and the like, she also indicates her disalignment with the statement made by the host.

\section{Displaying Modesty}

Multiple preference principles sometimes cannot be satisfied concurrently. For example, two principles will cooperate in the case of a compliment where conflicting preferences occur, with one principle dealing with the preference for agreement with the previous assessment and the other relating to the avoidance or minimization of self-praise (Pomerantz \& Heritage, 2013). In these cases, some compromise solutions, such as plain disagreement and shifts of praise to third parties, can be used (Pomerantz, 1978).

Excerpt 11

$01 \mathrm{H}: \quad$ You look gorgeous as always $\uparrow$

$02 \mathrm{G}: \rightarrow$ My skirt $>$ is $<$ too short

Excerpt 12

$01 \mathrm{H}$ : You look amazing

$02 \mathrm{G}: \rightarrow$ Stop it

$03 \mathrm{H}$ : You look amazing

$04 \mathrm{G}: \rightarrow$ Stop it

$05 \mathrm{H}:$ I love the dre- I love the whole- $>$ er $<$ the dress is gorgeous, you look fantastic=

$06 \mathrm{G}: \rightarrow=$ There's a whole team of people back there that ${ }^{\circ}$ help ${ }^{\circ}$ it's not me

In the exchange exhibited by Excerpt 11, the guest shifts the assessment of her appearance made by the host to the assessment of the size of her skirt, instead of explicitly accepting or rejecting the compliment paid by the host, which is in line with the compromise solution of shifts (ibid.). Likewise, in the exchange displayed by Excerpt 12, each time the host compliments the guest on her appearance $(01 \& 03)$, the guest tries to stop the progression of the topic (02 \& 04$)$, which is somewhat equivalent to disagreement with the prior assessments made by the host. After the host shifts to make an assessment of the guest's dress (05), the guest still does not accept it but attributes her beautiful appearance to the help of a third party - her clothing team. In the two exchanges presented by the above excerpts, the preference for agreement is adjusted for a display of modesty (Pomerantz \& Heritage, 2013).

\section{CONCLUSION}

Various factors can underlie the delivery of dispreferred responses in social interaction: an interactant may deliver a dispreferred response when he or she does not have the relevant knowledge to provide an expected response to the prior utterance; a dispreferred response can also be made to indicate an interactant's disalignment with the interlocutor or to show the modesty of an interactant.

Some practices may be performed by interactants in delivering dispreferred responses, including delaying the occurrences of dispreferred responses and blurring them through mitigating devices. Therefore, dispreferred responses are not necessarily destructive to the smooth progression of social interaction or to the social solidarity of interactants as a result of the various devices interactants can use to mitigate the force of dispreference and to minimize potential threats to the face of interlocutors.

\section{REFERENCES}

[1] Atkinson, J. M. \& Heritage, J. (1984). Structures of social action: Studies in conversation analysis. Cambridge: Cambridge University Press.

[2] Bilmes, J. (1988). The concept of preference in conversation analysis. Language in Society, 17(2), 161-181.

[3] Drew, P. (2004). Conversation analysis. In K. L. Fitch \& R. E. Sanders (Eds.), Handbook of language and social interaction (pp. 71-102). London: Psychology Press.

[4] Englert, C. (2010). Questions and responses in Dutch conversations. Journal of Pragmatics, 42(10), 2666-2684.

[5] Heritage, J. (1984). Garfinkel and ethnomethodology. Cambridge: Polity Press.

[6] Hutchby, I. \& Wooffitt, R. (1998). Conversation analysis. Cambridge: Polity Press.

[7] Molenaar, N. J. \& Smit, J. H. (1996). Asking and answering yes/no-questions in survey interviews: A conversational approach. Quality \& Quantity, 30(2), 115-136.

[8] Park, Y. (1998). A discourse analysis of contrastive connectives in English, Korean, and Japanese conversation: With special reference to the context of dispreferred responses. In A. H. Jucker \& Y. Ziv. (Eds.), Discourse markers: Descriptions and theory (pp. 277-300). Amsterdam: John Benjamins.

[9] Pomerantz, A. (1978). Compliment responses: Notes on the co-operation of multiple constraints. In J. Schenkein (Ed.), Studies in the organization of conversational interaction (pp. 79-112). New York, NY: Academic Press.

[10] Pomerantz, A. (1984). Agreeing and disagreeing with assessments: Some features of preferred/dispreferred turn shape. In J. M. Atkinson, \& J. C. Heritage (Eds.), Structures of social action: Studies in conversation analysis (pp. 57-101). Cambridge: Cambridge University Press.

[11] Pomerantz, A. \& Heritage, J. (2013). Preference. In J. Sidnell \& T. Stivers (Eds.), The handbook of conversation analysis (pp. 
210-228). Chichester, UK: John Wiley \& Sons, Ltd.

[12] Rees-Miller, J. (2000). Power, severity, and context in disagreement. Journal of Pragmatics, 32(8), 1087-1111.

[13] Schegloff, E. A. (1990). On the organization of sequences as a source of "coherence" in talk-in-interaction. In R. Freedle (Ed.). Conversational organization and its development (pp. 51-77). Norwood, NJ: Ablex.

[14] Schegloff, E. A. (2007). Sequence organization in interaction: A primer in conversation analysis (Vol. 1). Cambridge: Cambridge University Press.

[15] Tanaka, H. (2005). Grammar and the "timing" of social action: Word order and preference organization in Japanese. Language in Society, 34(3), 389-430.

[16] Tanaka, H. (2008). Delaying dispreferred responses in English: From a Japanese perspective. Language in Society, 37(4), 487-513.

[17] Waring, H. Z. (2012). Doing disaffiliation with now-prefaced utterances. Language \& Communication, 32(3), $265-275$.

[18] Yu, G. \& Wu, Y. (2015). Managing awkward, sensitive, or delicate topics in (Chinese) radio medical consultations. Discourse Processes, 52(3), 201-225.

Chunxiao Wu was born in Taian, China in 1991. She received her Master degree in English language and literature from Shandong University, China in 2016.

She is currently a teaching assistant in the School of Foreign Languages, Taishan University, China. Her research interests include English teaching and conversation analysis. 